\title{
Changes in potential difference across the human buccal mucosa with buffered or unbuffered aspirin and salicylate
}

\author{
B J R WHITTLE,* K A MAKKI, AND J O'GRADY \\ From the Wellcome Research Laboratories, Beckenham, Kent, and \\ the Department of Clinical Pharmacology St. Bartholomew's Hospital, London
}

SUMmaRy The potential difference (PD) across the gastric mucosa is an index of mucosal integrity, and is lowered by topical application of irritants such as aspirin. There are basic similarities in the PD across the buccal and gastric mucosae, and we have therefore investigated the actions of various salicylates in buffered or un-buffered solution on buccal PD in human subjects. Aspirin (at pH 2) and soluble aspirin ( $\mathrm{pH} 4.4$ ) applied topically reduced buccal $\mathrm{PD}$, but this fall was abolished by buffering to $\mathrm{pH}$ 7. Sodium salicylate likewise reduced buccal PD at $\mathrm{pH} 4$ and $\mathrm{pH} 6$, but not when buffered to $\mathrm{pH} 7$. Two other soluble aspirin mixtures also reduced buccal PD, indicating insufficient buffering capacity to prevent topical irritancy. Ingestion of aspirin $(600 \mathrm{mg})$, avoiding topical contact with the buccal mucosa, did not alter buccal PD. Paracetamol applied topically likewise failed to reduce buccal PD. Measurement of buccal PD may be useful in the preliminary assessment of the gastrointestinal irritation provoked by anti-inflammatory and other compounds.

The transmural electropotential difference (PD) across the gastric mucosa has been used as an index of the integrity of the gastric mucosa in animals ${ }^{12}$ and man ${ }^{3-5}$. A reduction in gastric PD has been observed after the topical application of irritants such as aspirin, bile salts, and ethanol in animals ${ }^{12}$ and in man ${ }^{4-7}$. These effects occur concurrently with the other characteristics of gastric 'barrier' damage such as the back-diffusion of acid from the gastric lumen into the mucosa and the increase in luminal concentration of sodium ions ${ }^{8-10}$. Such changes in gastric PD also correlate with histologically demonstrable damage to the human mucosa after aspirin ingestion. ${ }^{7}$

Because of the basic similarities in the magnitude, polarity, and the responses of the PD across the buccal mucosa and the gastric mucosa in $\operatorname{man}^{11}$ it may be possible to predict easily the ability of aspirin-like drugs and other potentially irritant compounds to damage the gastric mucosa after topical application, by measuring changes in buccal

\footnotetext{
*Address for correspondence: B J R Whittle, Department of Prostaglandin Research, Wellcome Research Laboratories, Beckenham, Kent, BR3 3BS.

Received for publication 15 April 1981
}

mucosal PD. In the present study, we have therefore investigated the actions of various formulations of acetylsalicylic acid and sodium salicylate, and of paracetamol on buccal PD in man.

A preliminary report on this work was presented to the Clinical Section of the British Pharmacological Society. ${ }^{12}$

\section{Methods}

\section{POTENTIAL DIFFERENCE MEASUREMENTS}

Experiments were performed on a total of 50 healthy volunteers between the ages of 19 and 30 years to whom the protocol was explained and who gave their written informed consent. Subjects were required to refrain from taking any aspirin or aspirin-like drugs within one week of the study and any subject with a history of aspirin-sensitivity was excluded.

Buccal mucosal potential difference was measured essentially as described by Houston ${ }^{11}$ using a probe electrode constructed from a Perspex (lucite) tube which contained a silver-silver chloride junction contact with a short column of saline agar $(\mathrm{NaCl}$ $150 \mathrm{mmol} / \mathrm{l}$ with $2 \% \mathrm{w} / \mathrm{v}$ agar). The skin electrode 
was also constructed of Perspex and contained a silver-silver junction in contact with a layer of saline-agar (Fig. 1). This electrode was strapped over a bleb raised on the volar surface of the forearm by the intradermal injection of sterile saline solution $(150 \mathrm{mmol} / \mathrm{i}$; a procedure which eliminates the skin potential. ${ }^{13}$ Since changes in pressure on the mouth electrode have been shown to alter buccal PD measurements, ${ }^{11}$ a restraining device was tised upon which the head could rest. Buccal PD was recorded on a millivoltmeter (Orion, model 701) and displayed on a chart recorder (Fig. 1). The individual PD measurements, taken over a three minute period, varied by less than $2 \mathrm{mV}$ from the average value for that period.

The experimental protocol is shown in Fig. 1. The subject was required to rinse the mouth with deionised water $(20 \mathrm{ml})$, and, after expelling the contents, the buccal PD was measured at 30 second intervals over a three minute control period. The drug under study, dissolved or suspended in deionised water $(20 \mathrm{ml})$ immediately before use, was then swilled around the buccal cavity for three minutes, without the subject swallowing the liquid. The contents were expelled and the mouth rinsed with distilled water ( $100 \mathrm{ml}$ in consecutive $20 \mathrm{ml}$ aliquots) and the test buccal PD measured over a three minute period as before. The $\mathrm{pH}$ values of the test and reference solution, measured on a Radiometer P4M62 pH meter, remained steady over a 15 minute experiment period, and were not altered by a three minute contact with the buccal mucosa (three experiments).

\section{DRUGS}

Acetylsalicylic acid powder (Wellcome Research Laboratories), sodium salicylate (British Drug House), soluble aspirin tablets BP ( $300 \mathrm{mg}$; Boots Co. Ltd), aspirin tablets BP (300 mg; Boots Co. Ltd), paracetamol tablets (Boots Co. Ltd), Codis tablets (soluble aspirin $600 \mathrm{mg}$, codeine $12 \mathrm{mg}$; Reckitt and Colman), and Paxidine (soluble aspirin $500 \mathrm{mg}$, codeine $8 \mathrm{mg}$; Boots Co. Ltd).

\section{STATISTICAL EVALUATION}

From the values of buccal PD taken during the three minute measurement period, the average control and test values were calculated for that subject. The data from all subjects in each group is expressed in terms of buccal PD $(\mathrm{mV})$ or change in buccal PD $(\triangle \mathrm{mV})$ and shown as mean $\pm \mathrm{SE}$ mean of $(n)$ values. The statistical significance of the data was evaluated using Student's $t$ test for paired or unpaired data where appropriate. $\mathrm{P}<0.05$ was taken as significant.

\section{Results}

\section{EFFECTS OF SOLUBLE ASPIRIN}

Soluble aspirin tablets (300-1200 mg) added to deionised water $(20 \mathrm{ml})$ produced a solution of $\mathrm{pH} 4 \cdot 4-4 \cdot 5$. In a study using 11 subjects, soluble aspirin $(300 \mathrm{mg}$ ) did not significantly alter PD, whereas soluble aspirin $(600$ and $1200 \mathrm{mg}$ ) signifi-

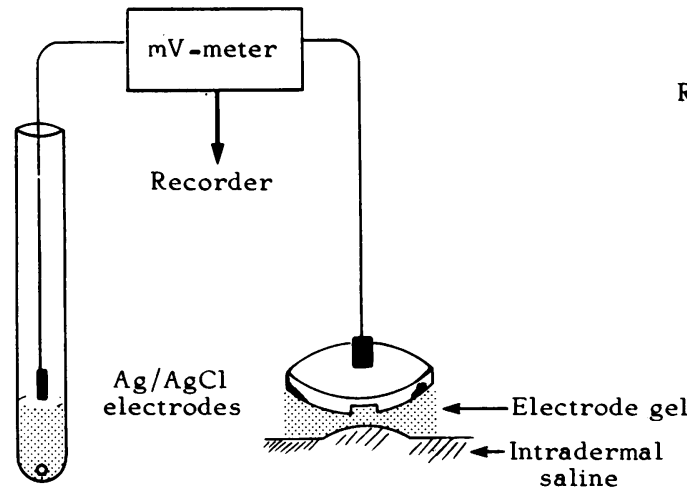

Mouth electrode

$\underline{\text { Skin electrode }}$

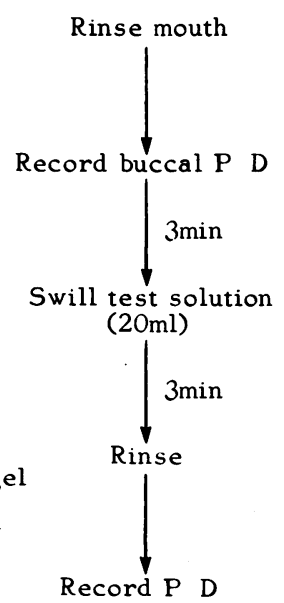

Fig. 1 Measurement of potential difference (PD) across the human buccal mucosa. 
cantly $(\mathrm{P}<0.01)$ reduced the PD $($ Table 1$)$. The change in PD was not significantly different $(P>0.05)$ between the $600 \mathrm{mg}$ or $1200 \mathrm{mg}$ dose of soluble aspirin.

In a series of experiments with another five subjects it was observed that, when the soluble aspirin $(600 \mathrm{mg})$ solution was buffered to $\mathrm{pH} 7 \cdot 2$ by the addition of sodium bicarbonate, the fall in PD was abolished (Table 2).

The changes in PD with soluble aspirin $(600 \mathrm{mg})$ in the two series of experiments shown in Tables 1 and $2(30-4$ and $19=3 \mathrm{mV})$ were not significantly

Table 1. Effect of soluble aspirin (BP), sodium salicylate, and buffered salicylate on PD across buccal mucosa in man.

\begin{tabular}{lccccc}
\hline Drug & Dose $(m g)$ & $p H$ & $\Delta P D(m)$ & $n$ & \\
\hline Soluble aspirin & 300 & $4 \cdot 5$ & $4 \cdots 2$ & 5 & NS \\
& 600 & $4 \cdot 5$ & $19=3$ & 11 & $\dagger$ \\
& 1200 & $4 \cdot 5$ & $15=2$ & 5 & $\dagger$ \\
& 1200 & $6 \cdot 3$ & $12 \approx 3$ & 8 & $*$ \\
Sodium salicylate & 1200 & $7 \cdot 3$ & $3=1$ & 5 & NS \\
Sodium salicylate & & & & & \\
$+\mathrm{NaHCO}_{3}$ & & & &
\end{tabular}

Data shown as change in PD ( $\triangle P D)$ are the mean $=S E$ mean from (n) subjects. The $\mathrm{pH}$ refers to the $\mathrm{pH}$ of the solution when the dose specified was suspended in $20 \mathrm{ml}$ distilled water. The level of statistical significance of the change in $P D$ from control values is shown by $* P<0.05 ;+P<0.01$.

Table 2. Effect of soluble aspirin, buffered soluble aspirin, and two soluble aspirin mixtures on buccal mucosal PD.

\begin{tabular}{|c|c|c|c|c|c|}
\hline Drug & Dose (mg) & $p H$ & $\triangle P D(m v)$ & $(n)$ & \\
\hline Soluble aspirin & 600 & $4 \cdot 5$ & $30 \div 4$ & 5 & + \\
\hline Soluble aspirin & 600 & & & & NS \\
\hline $\begin{array}{l}+\mathrm{NaHCO}_{3} \\
\text { Soluble aspirin }\end{array}$ & 600 & $7 \cdot 2$ & $2 \pm 3$ & 3 & NS \\
\hline + codeine (Codis) & 12 & $4 \cdot 3$ & $21=2$ & 5 & $\dagger$ \\
\hline $\begin{array}{l}\text { Soluble aspirin } \\
+ \text { codeine (Paxidine) }\end{array}$ & $\begin{array}{r}500 \\
8\end{array}$ & $4 \cdot 4$ & $20 \pm 1$ & 5 & $t$ \\
\hline
\end{tabular}

Results, shown as PD change, ( $\triangle P D$ ) are the mean $\mathrm{SE}$ mean from (n) subjects. The level of statistical significance of the change from control values is shown by $+P<0.01$.

Table 3. Buccal mucosal potential difference before and after treatment with sodium bicarbonate-citric acid and mixtures at various $\mathrm{pH}$ values.

\begin{tabular}{llll}
\hline$P D(m i)$ & & & \\
\hline$p H$ & Control & Test & \\
\hline 6.4 & $-39 \pm 6$ & $-38 \div 5$ & NS \\
4.6 & $-39=6$ & $-36 \pm 4$ & NS \\
2.6 & $-39-6$ & $-37 \div 6$ & NS
\end{tabular}

Results are shown as PD mean ... SE mean of values from seven subjects. In each case. there is no significant difference between control and test value. different from each other. However, to reduce any variation in the response of PD, comparisons between different drugs or treatments are best made using a crossover design within a given group of subjects.

\section{EFFECTS OF ASPIRIN}

In a study using seven subjects, aspirin powder $(1200 \mathrm{mg})$ suspended in deionised water $(20 \mathrm{ml})$ giving a $\mathrm{pH}$ of $2 \cdot 4$, produced a marked fall in PD (Fig. 2). A comparable fall was observed with soluble aspirin $(1200 \mathrm{mg}, \mathrm{pH} 4.5)$ as found in the previous studies. However, when the aspirin powder $(1200 \mathrm{mg})$ was dissolved in sodium bicarbonate solution to give a final solution of $\mathrm{pH} 7 \cdot 2$, no significant fall in buccal PD was observed (Fig. 2).

In control experiments on these seven subjects, solutions adjusted to $2 \cdot 6,4 \cdot 6$, and $6 \cdot 4$ with citric acid and solium bicarbonate had no significant effect on control buccal PD (Table 3).

\section{EFFECTS OF SODIUM SALICYLATE}

Sodium salicylate $(1200 \mathrm{mg})$ dissolved in deionised water, and adjusted to $\mathrm{pH} 4.4$ with citric acid produced a significant fall in buccal PD in seven subjects (Fig. 2). In another series of eight subjects, the fall in PD produced by sodium salicylate $(1200$ $\mathrm{mg}$ ) at $\mathrm{pH} 6.3$ was abolished when the solution was adjusted to $7 \cdot 3$ with sodium bicarbonate (Table 1).

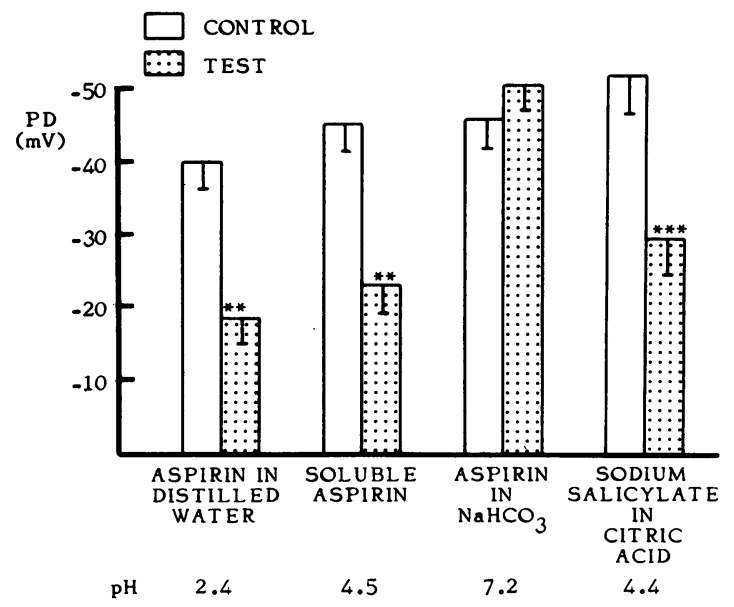

Fig. 2 Effect of aspirin, soluble aspirin, buffered aspirin, and sodium salicylate $(1 \cdot 2 \mathrm{~g})$ on buccal mucosal potential difference $(P D)$ in seven subjects. Results are shown as mean SE mean where the level of the statistical significance is shown by ${ }^{* *} \mathrm{P}<0.01$; $* * * \mathrm{P}<0.001$. 
EFFECTS OF SOLUBLE ASPIRIN-CODEINE MIXTURES

In another five subjects, the actions of two proprietary mixtures of soluble aspirin and codeine were investigated. As shown in Table 2, these mixtures gave solutions of $\mathrm{pH} 4 \cdot 3-4 \cdot 4$ and produced a significant fall in buccal PD.

EFFECTS OF SYSTEMICALLY-ADMINISTERED ASPIRIN

To determine whether the effect of aspirin was solely a topical action on the buccal mucosa, three subjects rapidly swallowed two intact aspirin tablets $(600 \mathrm{mg})$ with a draught of water $(50 \mathrm{ml})$ avoiding any prolonged contact with the buccal cavity, after control values of buccal PD had been measured. Thirty minutes after aspirin ingestion, a time close to the peak plasma levels of aspirin, ${ }^{14}$ buccal PD was again determined. There was no significant change in the post-aspirin value $(-42 \pm$ $5 \mathrm{mV}$ ) as compared with the pretreatment control value $(-38 \pm 4 \mathrm{mV} ; \mathrm{P}>0.05)$.

\section{EFFECT OF PARACETAMOL}

In another three subjects, a suspension of paracetamol $(500 \mathrm{mg})$ in deionised water $(20 \mathrm{ml} ; \mathrm{pH} 4.7)$ had no significant effect $(P>0.05)$ on buccal PD (PD was $-39 \pm 4 \mathrm{mV}$ before and $-36 \pm 3 \mathrm{mV}$ after paracetamol).

\section{Discussion}

The present study confirms the findings of Houste ${ }^{11}$ that, like other areas of the gastrointestinal tract, ${ }^{15}$ the human buccal mucosa generates a significant bioelectric potential difference (PD). The magnitude and polarity of this PD $(-35$ to $-55 \mathrm{mV})$ is comparable with that reported for the human gastric mucosa by Andersson and Grossman, ${ }^{3}$ and others. The ionic basics of the gastric mucosal PD is not clearly defined but involves the flux of ions including $\mathrm{H}^{+}, \mathrm{Na}^{+}$, and $\mathrm{CI}^{-}$, and, because of the different environment of stomach and buccal cavity, it is unlikely that the ionic mechanisms underlying buccal PD are comparable. Nevertheless, acetylsalicylic acid in acidic solution can reduce buccal PD, as found with human gastric PD. ${ }^{4-6}$ Light microscopy studies have shown areas of cellular disruption and microscopic erosions which accompany such changes in gastric mucosal $\mathrm{PD}^{7}$ and likewise the change in buccal PD may reflect topical irritation, as other studies have shown that aspirin can cause cellular damage when applied to the buccal mucosa. ${ }^{16}$ The fall in buccal PD appears to depend on the presence of free $\mathrm{H}^{+}$, as the fall in PD induced by aspirin $\because$ as abolished hy pr:fiering the solution to $\mathrm{pH} 7$ with sodium bicarbonate; this was also ivin. gastric mucosa by both Murray et al, ${ }^{5}$ and Bowen et al. ${ }^{7}$ In control experiments, acidic solutions alone did not alter buccal PD. In the current study, the abolition of the PD response to aspirin in neutral solution did not appear to depend solely on the reduction of the lipid soluble non-dissociated species. A marked fall in PD was observed at both pH 2.5 and 4.5 and, as aspirin has a dissociation constant (pka) of $3 \cdot 5$, this represents a degree of ionisation of $10 \%$ and $90 \%$ respectively.

Sodium salicylate also caused a significant fall in buccal PD at $\mathrm{pH} 4.4$ and $\mathrm{pH} 6.3$, but not when buffered to $\mathrm{pH} 7 \cdot 2$. Salicylate likewise reduces PD across the canine gastric mucosa, ${ }^{17}$ which again may reflect topical irritation in the presence of luminal $\mathrm{H}^{+}$ions.

The fact that PD across the gastric or buccal mucosa did not change with highly buffered aspirin could suggest that formulations of aspirin or similar drugs providing a neutral $\mathrm{pH}$ would have less acute topical gastric irritancy. In the current study, soluble aspirin BP and two proprietary aspirincontaining mixtures giving solutions of $\mathrm{pH} 4$ provoked falls in PD indicating that the buffering capacity of the mixtures was insufficient. Reformulation of soluble aspirin BP, as well as certain proprietary soluble aspirin mixtures, may be indicated. Furthermore, the buffering capacity of new formulations must take into account the low $\mathrm{pH}$ of the gastric contents and must be sufficient to raise the gastric $\mathrm{pH}$ to neutrality. Thus, it has been shown that oral administration of a highly buffered aspirin mixture does not reduce human gastric PD. ${ }^{5}$ Although acute administration of a relatively low dose of buffered aspirin mixture has been reported to cause negligible damage to the gastric mucosa, as assessed by histological examination, ${ }^{7}$ a recent study indicated that in higher doses $(3.9 \mathrm{~g}$ per day) buffered aspirin offered little or no protection to the gastric and duodenal mucosa ${ }^{18}$. Enteric coated tablets did appear, however, to cause less irritation. ${ }^{1 \times 19}$ In the present study, paracetamol also failed to reduce buccal PD, perhaps reflecting its less irritant action on the buccal mucosa, as suggested for the gastric mucosa.

On chronic administration, topical irritation of the gastric mucosa by non steroid anti-inflammatory agents is likely to be only one of the factors provoking gastrointestinal damage. Thus sodium salicylate, which, like aspirin, can reduce gastric PD and initiate back-diffusion of hydrogen ions across the mucosa, ${ }^{17}$ causes less gastrointestinal 
bleeding than aspirin (as determined by faecal excretion of $\mathrm{Cr}^{51}$ labelled erythrocytes) when administered to man. ${ }^{20} 21$ Interestingly, sodium salicylate, unlike aspirin, does not inhibit prostaglandin cyclo-oxygenase (the enzyme responsible for the biosynthesis of prostaglandins) in the gastrointestinal tract, when administered in antiinflammatory doses in the rat. ${ }^{22}{ }^{23}$ This suggests that the fall in gastric or buccal PD after topical application of sodium salicylate is not a consequence of inhibition of prostaglandin biosynthesis. Such a suggestion is supported in the current work where systemic pre-treatment with aspirin (avoiding local contact with the buccal mucosa) failed to change buccal PD at a time of peak aspirin plasma levels, although it is not known how the buccal tissue levels of aspirin so obtained compare with those after local administration. Likewise, Ivey and colleagues ${ }^{2+}$ have shown that intravenously-administered aspirin, in doses which should be sufficient to inhibit endogenous prostaglandin synthesis, failed to alter gastric PD in man, as also shown in animal studies by Bugat and co-workers. ${ }^{25}$ These findings could also suggest that endogenous prostaglandin formation is not a major factor in maintaining the PD across the gastric or buccal mucosa.

From our previous studies, it was suggested that topical irritation, as reflected by changes in PD and acid back diffusion, is insufficient to initiate marked gastric bleeding, but, when combined with the inhibition of gastric mucosal prostaglandin formation, it leads to extensive gastric damage. ${ }^{26}$ Thus, reduction of topical irritancy alone is unlikely to provide non-steroid anti-inflammatory agents devoid of gastrointestinal toxicity, and animal studies have clearly demonstrated that aspirin and similar compounds can cause gastric damage when administered by the intravenous route. ${ }^{25} 26$ The rational development of nonsteroid anti-inflammatory drugs for clinical use with less gastrointestinal toxicity should therefore encompass elimination of both the inhibitory effects on gastrointestinal prostaglandin production and also the topical irritant actions. Our recent studies have suggested that anti-inflammatory compounds which selectively inhibit prostaglandin production at inflammatory sites yet do not inhibit prostaglandin production in the gastrointestinal tract can be achieved. ${ }^{22}$ Such compounds can then be formulated to reduce or prevent any topical irritancy, if present.

Although the ionic basis for the buccal PD is as yet unknown, the present findings suggest that studies on human buccal PD may be predicative of local irritant effects on the gastric mucosa and may provide a rapid, preliminary assessment of the activity of newer anti-inflammatory compounds before detailed studies on the human gastric mucosa.

We are grateful to Dr E Letley, Department of Clinical Pharmacology, Wellcome Research Laboratories, for his assistance in some of these experiments.

\section{References}

'Davenport HW, Warner HA, Code CF. Functional significance of gastric mucosal barrier to sodium. Gastroenterolog. 1964; 47: 142-52.

'Chvasta TE, Cooke AR. The effect of several ulcerogenic drugs on the canine gastric mucosal barrier. J Lab Clin Med 1972; 79: 302-15.

${ }^{3}$ Andersson S, Grossman MI. Profile of $\mathrm{pH}$, pressure, and potential difference at gastroduodenal junction in man. Gastroenterology 1965; 49: 364-71.

${ }^{+}$Geall MG, Phillips SF, Summerskill DM. Profile of gastric potential difference in man-effects of aspirin, alcohol, bile and endogenous acid. Gastrocnterology. 1970; 38: 437-43.

"Murray HS, Strottman MP, Cooke AR. Effect of several drugs on gastric potential difference in man. Br: Med J 1974; 1: 19-21.

"Cochran KM, Mackenzie JF, Russell RI. Role of taurocholic acid in production of gastric mucosal damage after ingestion of aspirin. $B r$ Med $J$ 1975; 1 : 183-85.

'Bowen BK, Krause WJ, Ivey KJ. Effect of sodium bicarbonate on aspirin-induced damage and potential difference changes in human gastric mucosa. $\mathrm{Br}$. Med $\mathrm{J}$ 1977; 2: 1052-55.

${ }^{\text {}}$ Davenport HW. Gastric mucosal injury by fatty and acetylsalicyclic acids. Gastroenterology 1964; 46: $245-53$.

${ }^{9}$ Smith BM, Skillman JJ, Edwards BG, Silen W. Permeability of the human gastric mucosa: alteration by acetylsalicylic acid and ethanol. $N$ Engl $J$ Med 1971; 285: 716-21.

${ }^{10}$ Ivey KJ, Morrison S, Gray C. Effect of intravenous salicylates on the gastric mucosal barrier in man. Am J Dig Dis 1972; 17: 1055-64.

${ }^{11}$ Houston GJ. The effects of aspirin, ethanol, indomethacin and $9 x$-fludrocortisone on buccal mucosal potential difference. Br J Clin Pharmacol 1978; 5: $153-60$.

${ }^{12}$ Makki KA, Whittle BJR, O'Grady J. Effects of buffered aspirin and salicylate on the bio-electric potential difference across the human buccal mucosa. Br J Clin Pharmacol 1979; 8: 393-4P.

${ }^{13}$ Grantham RN, Code CF, Schleyel JF. Reference electrode sites in determination of potential difference across the gastro-oesophogeal mucosal junction. Mayo Clin Proc 1970; 45: 265-74.

${ }^{14}$ Lo YE, Bye A. Specific and sensitive method for the determination of aspirin and salicylic acid in plasma using reversed-phase high performance liquid chromatography. J Chromatogr 1980; 181: 473-77.

${ }^{15}$ Wingate DL. Electro-potential difference in the 
gastro-intestinal tract: present status. Acta Hepatogastroenterol 1975; 22: 200-5.

${ }^{16}$ Roth JL, Valdes-Dapena A, Pieses P, Buchman E. Topical action of salicylate in gastro-intestinal erosion and hemorrhage. Gastroenterology 1963; 44: 146-58.

${ }^{17}$ Davenport HW. Damage to the gastric mucosa: effects of salicylates and stimulation. Gastroenterolog.' 1965; 49: 184-96.

18 Lanza FL, Royer GR, Nelson AS. Endoscopic evaluation of the effects of aspirin, buffered aspirin, and enteric coated aspirin on gastric and duodenal mucosa. $N$ Engl J Med 1980; 303: 136-8.

${ }^{19}$ Hoftiezer JW, Silvoso GK, Burks M, Ivey KJ. Comparison of the effects of regular and enteric-coated aspirin in gastro-duodenal mucosa of man. Lancet 1980; 2: 609-12.

${ }^{20}$ Grossman MI, Matsumoto KK, Lichter RJ. Fecal blood loss produced by oral and intravenous administration of various salicylates. Gastroenterology 1961; 40: 383-8.

${ }^{21}$ Leonards JR, Levy G. Gastrointestinal blood loss from aspirin and sodium salicylate tablets in man. Clin Pharmacol Ther 1973; 14: 62-6.

${ }^{22}$ Whittle BJR, Higgs GA, Eakins KE, Moncada S, Vane JR. Selective inhibition of prostaglandin production in inflammatory exudates and gastric mucosa. Nature 1980; 284: 271-3.

${ }^{23}$ Eakins KE, Higgs GA, Whittle BJR. Differential effects of sodium salicylate and BW $755 \mathrm{C}$ on prostaglandin formation in inflammatory exudates and the gastrointestinal tract. Br.J Pharmacol 1980; 70: 82-3P.

${ }^{24}$ Ivey KJ, Paone DB, Krause WJ. Acute effect of systemic aspirin on gastric mucosa in man. Dig Dis Sci 1980; 25: 97-9.

${ }^{25}$ Bugat R, Thompson MR, Aures D, Grossman MI. Gastric mucosal lesions produced by intravenous infusion of aspirin in cats. Gastrocnterology 1976; 71: 754-9.

${ }^{26}$ Whittle BJR. Mechanisms underlying gastric mucosal damage unduced by indomethacin and bile salts, and the actions of prostaglandins. $\mathrm{Br} J$ Pharmacol 1977; 60: $455-60$. 